\title{
SOMATIC HYBRIDISATION USING A DOUBLE MUTANT OF NICOTIANA TABACUM
}

\author{
D. PENTAL, J. D. HAMILL AND E. C. COCKING \\ Plant Genetic Manipulation Group, Department of Botany, University of Nottingham, \\ Nottingham NG7 2RD, U.K.
}

Received 27.x.83

\section{SUMMARY}

\begin{abstract}
Leaf mesophyll protoplasts of a nitrate reductase deficient, streptomycin resistant double mutant of Nicotiana tabacum were fused with cell suspension protoplasts of wild type $N$. rustica. Hybrid colonies were selected for nitrate reductase proficiency and streptomycin resistance. Green, actively proliferating colonies were recovered in the selection medium. Eleven of twenty green colonies, transferred to regeneration medium, produced plants. Regenerated plants were analysed for their vegetative and floral characteristics, Fraction 1 protein polypeptide composition and leaf esterases. All the eleven regenerants were nuclear somatic hybrids possessing the chloroplast of the $N$. tabacum parent. By developing a double mutant with a negative (auxotrophic) and a positive (resistance) selection marker in a species of interest, this species can be hybridised by somatic cell fusion with wild type species lacking selectable markers.
\end{abstract}

\section{INTRODUCTION}

Successful somatic cell hybridisation requires a selection system capable of recovering small numbers of hybrid cells from amongst a large population of parental cells. Previously, mutants have been hybridised with other mutants to recover hybrids by genetic complementation (Melchers and Labib, 1974; Douglas et al., 1981) or hybridised with species which have constraints of limited growth (Power et al., 1980) or lack of regeneration in certain nutrient media (Maliga et al., 1977). Such selection methods require the development of new mutants, or markers based on differential growth responses, for each combination of species. We proposed an alternative approach which involves combining an auxotrophic mutant and a dominant resistance mutant in a single species to produce a double mutant (Pental et al., 1982a; Hamill et al., 1983). Once such a double mutant is produced, it can be hybridised with wild type species, eliminating the necessity for any other selectable markers. To test this proposal we have fused leaf protoplasts of a nitrate reductase deficient, streptomycin resistant double mutant of Nicotiana tabacum ( $\mathrm{NR}^{-} \mathrm{SR}^{+}$) with cell suspension protoplasts of wild type Nicotiana rustica, and shown that it is possible to select somatic hybrids between these two species.

N. tabacum $\mathrm{NR}^{-} \mathrm{SR}^{+}$was produced by sexually crossing streptomycin resistant $N$. tabacum SRI ( $($ ) with nitrate reductase deficient $N$. tabacum nia-130 (ठ) (Hamill et al., 1983). In N. tabacum $\mathrm{NR}^{-} \mathrm{SR}^{+}$, nitrate reductase deficiency is due to recessive mutations in two genes in the nuclear genome, and streptomycin resistance is due to a mutation in the chloroplast genome. Cell colonies derived from protoplasts of $N$. tabacum $\mathrm{NR}^{-} \mathrm{Sr}^{+}$can be selected against by placing them in a medium containing nitrate as the sole source of nitrogen. Alternatively, such colonies can be positively selected by placing them in a medium containing streptomycin. 


\section{Materials AND Methods}

\section{(i) Growth of plant material and protoplast isolation}

The nitrate reductase deficient, streptomycin resistant double mutant plants of Nicotiana tabacum $\mathrm{NR}^{-} \mathrm{SR}^{+}$were grown in hydroponics as previously described (Hamill et al., 1983). Protoplasts were isolated from leaf mesophyll of $N$. tabacum $\mathrm{NR}^{-} \mathrm{SR}^{+}$as described previously for the nitrate reductase deficient nia-130 mutant of $N$. tabacum (Pental et al., 1982b).

Callus induction, cell suspension formation and protoplast isolation of $N$. rustica cv V12 was as described for $N$. alata (Berry et al., 1983). Protoplasts of $N$. rustica were isolated from 2-3 months old cell suspensions.

\section{(ii) Fusion of protoplasts, culture of protoplasts, and selection of} somatic hybrid calli

Fusions were carried out between leaf mesophyll protoplasts of $N$. tabacum and cell suspension protoplasts of $N$. rustica following the high $p \mathrm{H} / \mathrm{Ca}^{++}$method (Keller and Melchers, 1973). Frequencies of heterokaryon formation were calculated by microscopic observation of the number of intact heterokaryons present among intact parental protoplasts 12 hours after culturing the post fusion protoplast mixture. Heterokaryons were recognised by the presence of chloroplasts of the mesophyll parent and dense cytoplasmic strands of the cell suspension parent.

After fusion treatment, protoplasts were suspended in MS-1 mediumMurashige and Skoog (1962) medium modified by omitting inorganic nitrogen and by the addition of $6 \mathrm{mM}$ L-glutamine, $2 \mathrm{mM}$ L-aspartic acid, $1 \mathrm{mM} \mathrm{L}$-arginine and $0.1 \mathrm{mM}$ glycine, with $2 \mathrm{mg} \mathrm{l}^{-1} \mathrm{NAA}(\alpha$ napthaleneacetic acid) and $0.5 \mathrm{mg} \mathrm{l}^{-1}$ BAP (6-benzylaminopurine) containing 9 per cent w/v mannitol, $p \mathrm{H} 5.8$ before filter sterilisation. Protoplasts were cultured in $5 \mathrm{~cm}$ petri dishes (A/S Nunclon Kamstrup, Roskilde, Denmark), in $4 \mathrm{ml}$ of liquid MS- 1 medium over $4 \mathrm{ml}$ of MS-1 medium solidified with 0.6 per cent w/v agar (Sigma) in continuous light (600 lux) at $24 \pm 2{ }^{\circ} \mathrm{C}$. Initial plating densities of protoplasts were $5 \times 10^{4}$ protoplasts $/ \mathrm{ml}$ in the liquid layer.

After the protoplasts had developed into small cell colonies (10-12 days of culture, approximately 30 cells), the cultures were transferred to a selection medium designated as MS-2-MS medium modified by using $38 \mathrm{mM}$ $\mathrm{KNO}_{3}$ instead of the usual concentrations of $\mathrm{NH}_{4} \mathrm{NO}_{3}$ and $\mathrm{KNO}_{3}, 1 \mathrm{mM}$ streptomycin sulphate with $0.1 \mathrm{mg} \mathrm{l}^{-1} \mathrm{NAA}$ and $0.5 \mathrm{mg} \mathrm{l}^{-1}$ BAP containing 4.5 per cent $\mathrm{w} / \mathrm{v}$ mannitol, $p \mathrm{H} 5.8$ before filter sterilisation. Colonies were cultured in $10 \mathrm{ml}$ of MS-2 medium, placed over $10 \mathrm{ml}$ of MS-2 medium solidified with $0.6 \mathrm{w} / \mathrm{v}$ agar, at a plating density of $10^{3}$ colonies $/ \mathrm{ml}$ in the liquid layer in $9 \mathrm{~cm}$ petri dishes (Sterilin Ltd., Teddington, U.K.) under constant fluorescent light $(2000 \mathrm{lux})$ at $24 \pm 2^{\circ} \mathrm{C}$. Osmoticum in the medium was lowered as previously described (Pental et al., 1982b)

\section{(iii) Shoot regeneration and transfer to the greenhouse}

Green colonies recovered from the selection medium and which were approximately $10 \mathrm{~mm}$ in diameter were transferred to shoot regeneration medium MS-3-MS medium containing $0.5 \mathrm{mg} \mathrm{l}^{-1}$ BAP and $2 \mathrm{mg} \mathrm{l}^{-1}$ IAA 


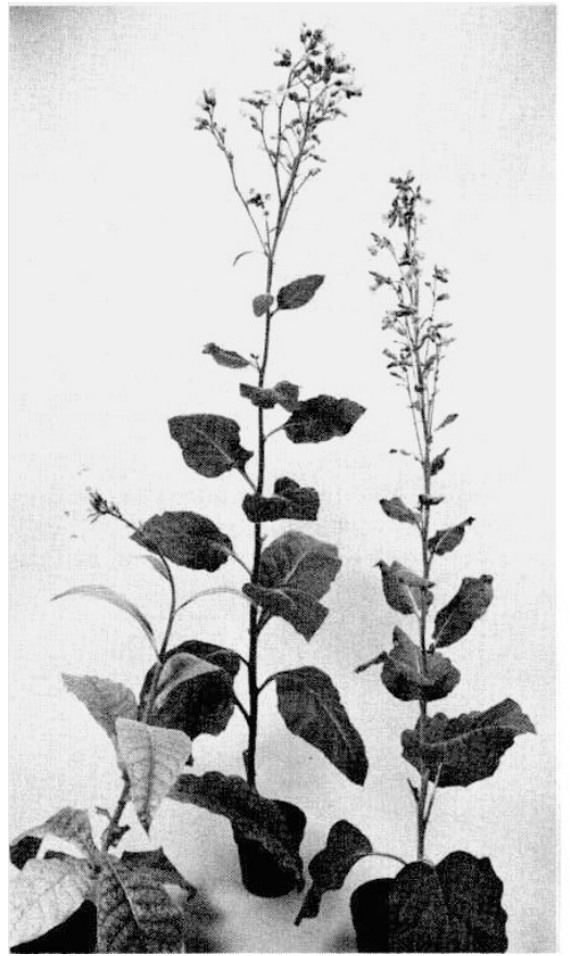

(a)

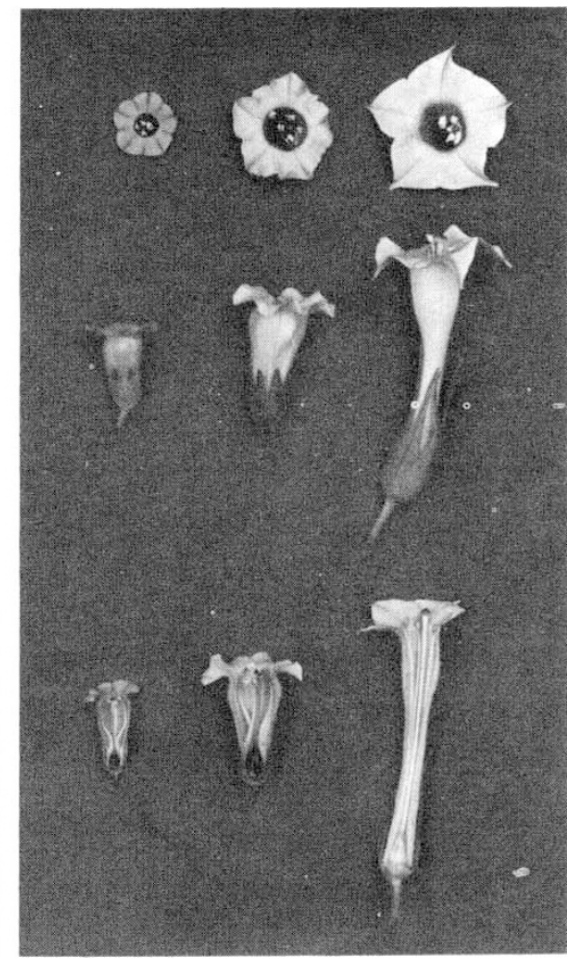

(b)

Plate 1(a). General vegetative and floral morpholngy (left to right) of nitrate reductase deficient streptomycin resistant double mutant of $N$. tabacum $\mathrm{NR}^{-} \mathrm{SR}^{+}$, a somatic hybrid and $N$. rustica parent. $N$. tabacum $\mathrm{NR}^{-} \mathrm{SR}^{+}$is a dwarf plant and shows chlorisis of leaves due to nitrogen deficiency. The dwarf character of $N$. tabacum $\mathrm{NR}^{-} \mathrm{SR}^{+}$is inherited from its maternal plant $N$. tabacum SRI which is a dwarf tobacco. The hybrid plant shows heterotic vigour in its vegetative growth.

PLATE 1(b). Floral morphology (left to right) of $N$. rustica, a somatic hybrid and $N$. tabacum $\mathrm{NR}^{-} \mathrm{SR}^{+}$. Hybrid flower is intermediate in characteristics, and has a black-walled ovary like the $N$. rustica parent. 


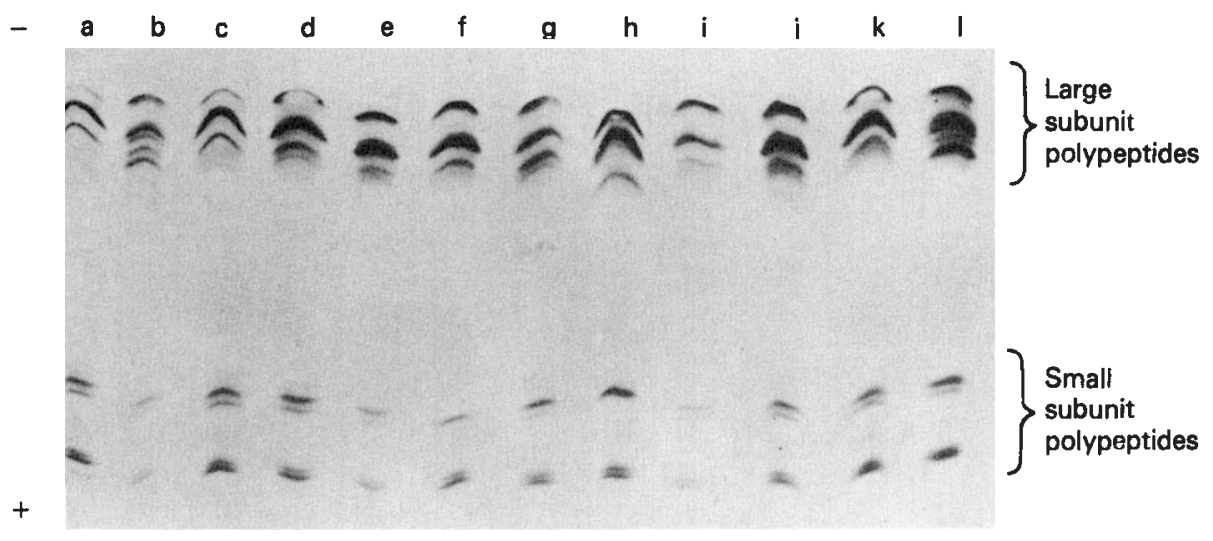

$2 a$

PLATE 2(a). Isoelectric focusing of Fraction 1 protein of $N$. tabacum $\mathrm{NR}^{-} \mathrm{SR}^{+}$(lane f), $N$. rustica (lane $\mathrm{h}$ ) and hybrids 1-10 (lanes a-e, g, i-l). All the ten hybrids possess the chloroplast encoded large subunit polypeptides of $N$. tabacum, and the nuclear encoded small subunit polypeptides of both the parents. Hybrid 11 was analysed on another gel and was found to have a band pattern similar to the hybrids illustrated.

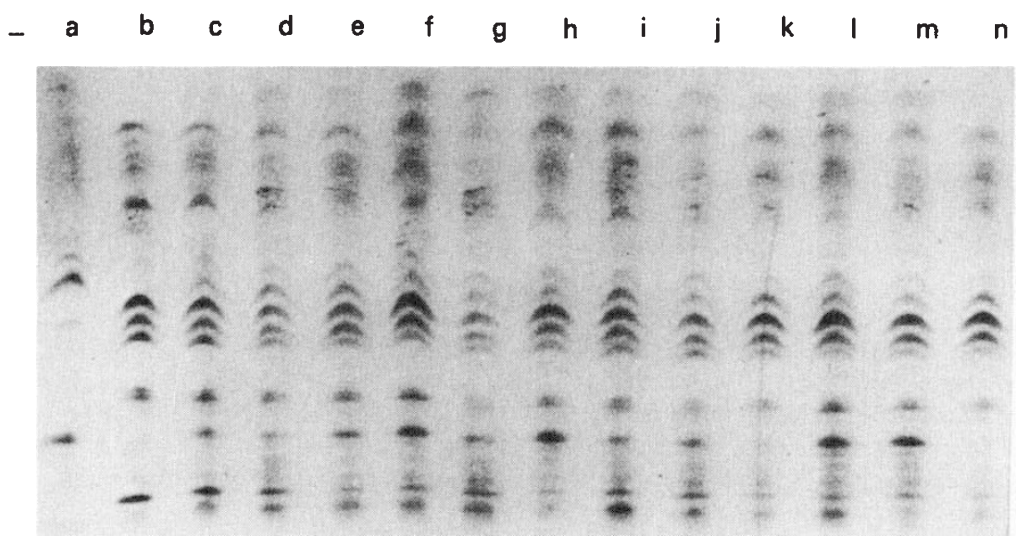

$2 \mathrm{~b}$

PLATE 2(b). Isoelectric focusing of leaf esterases of $N$. rustica (lane a), $N$. tabacum $\mathrm{NR}^{-} \mathrm{SR}^{-}$ (lane b), mixture of $N$. rustica, N. tabacum (lane c) and somatic hybrids 1-11 (lanes d-n). All the eleven regenerants possess bands characteristic of both the parents. Hybrids 8 (lane k) and 11 (lane n) lack a $N$. rustica parental band showing variability amongst the hybrids. 
(indole-3-acetic acid), $p \mathrm{H} 5 \cdot 8$ before autoclaving. Cultures were maintained at $24 \pm 2{ }^{\circ} \mathrm{C}$ under constant fluorescent light of 3000 lux.

Regenerated shoots were excised and grown on MS medium solidified with agar. When the shoots were $5 \mathrm{~cm}$ or more in height, and had developed roots, they were transferred to the greenhouse and grown as for wild type N. tabacum (Pental et al., 1982b).

\section{(iv) Analysis of plants for evidence of hybridity}

Plants regenerated from selected colonies were characterised for their vegetative and floral morphology.

Plants were also characterised biochemically by isoelectric focusing of Fraction 1 protein polypeptides and leaf esterases. Fraction 1 protein analysis was carried out using the method of Cammaerts and Jacobs (1980). Polymerisation of isoelectric focusing gels was done with ammonium persulfate instead of riboflavine.

For analysis of leaf esterases, proteins were extracted from plants at the flowering stage. Extraction buffer was the same as used for Fraction 1 protein analysis. A sample of $100 \mu \mathrm{g}$ protein, as measured by the method of Lowry et al. (1951), was applied to $0.5 \mathrm{~mm}$ thick pre-cast polyacrylamide gels ( $p \mathrm{H}$ gradient $3 \cdot 5-9 \cdot 5$, LKB). Isoelectric focusing was performed for $4 \mathrm{~h}\left(1500 \mathrm{~V}\right.$, max current $\left.15 \mathrm{~mA}, 10^{\circ} \mathrm{C}\right)$ and the gel was stained for esterase isoenzymes by the method of Smith et al. (1970).

\section{Results}

\section{(i) Selection of hybrids}

Fusion experiments, involving leaf mesophyll protoplasts of $N$. tabacum $\mathrm{NR}^{-} \mathrm{SR}^{+}$and cell suspension protoplasts of $N$. rustica, gave rise to colonies in MS-1 medium. A total of $10^{6}$ protoplasts of each species was fused. Heterokaryon formation frequency was 1 per cent. After 10 days growth, colonies were transferred to selection medium MS-2. Each selection dish contained about $10^{4}$ colonies at a density of $10^{3} / \mathrm{ml}$ of MS-2 medium. After 4-5 wk in MS-2 medium, green colonies were evident in fusion dishes, but none were present in non-fused mixtures of parental protoplasts. On average, twelve green colonies were observed in each selection dish. As the initial heterokaryon frequency was 1 per cent, about 12 per cent heterokaryons gave rise to colonies capable of growing in the selection medium.

Green colonies were maintained individually on the selection medium, and a sample of twenty colonies was transferred to MS-3 medium for shoot regeneration. Eleven out of twenty colonies regenerated shoots on MS-3 medium. One representative shoot was excised from each regenerating callus and transferred to MS medium where they grew further and rooted. All the eleven representative plants were transferred to a greenhouse.

\section{(ii) Characterisation of hybrids}

Regenerated plants showed vigorous vegetative growth and flowered (plate 1(a)). The floral morphology of regenerated plants with respect to the form of the inflourescence, the corolla length and its width and shape, was intermediate (plate 1(a), (b)). The flowers of the regenerated plants had 
black walled ovaries like the $N$. rustica parent (plate $1(\mathrm{~b})$ ). The black ovary is due to a dominant nuclear allele in the $N$. rustica genome (Jinks et al., 1981).

Isoelectric focusing of Fraction 1 protein (Ribulose bisphosphate carboxylase) of the eleven regenerants showed them to possess the chloroplast encoded large subunit polypeptides of $N$. tabacum and the nuclear encoded small subunit polypeptides of both the parents (plate 2(a)). Isoelectric focussing of leaf esterases showed all the eleven regenerants to possess bands characteristic of both parents (plate 2(b)).

\section{Discussion}

On the basis of their floral morphology and biochemical analysis we conclude that all eleven plants regenerated from colonies capable of growing in the selection medium possessed the nuclear genomes of both parents and chloroplasts of $N$. tabacum. The latter characteristic was expected as the resistance to streptomycin is encoded by the chloroplast genome of $N$. tabacum $\mathrm{NR}^{-} \mathrm{SR}^{+}$(Hamill et al., 1983). Since the selection was for nitrate reductase proficiency and streptomycin resistance we expected plants regenerated from the selected colonies either to have the nuclear genome of both parents and chloroplasts of $N$. tabacum, or to have the nuclear genome of $N$. rustica and chloroplasts of $N$. tabacum. In $N$. tabacum and $N$. rustica fusions we did not find a combination of the latter type. We assume that the majority, if not all, of the green colonies, observed in the selection medium were somatic hybrids of $N$. rustica and $N$. tabacum.

The results from fusion of $N$. tabacum $\mathrm{NR}^{-} \mathrm{SR}^{+}$with $N$. rustica show that combining a negative (nitrate reductase deficiency) and a positive (streptomycin resistance) selection marker in the same $N$. tabacum genome provides a convenient selection method for studying genomic interactions of $N$. tabacum with other species which lack selectable markers, if the latter can utilise nitrate as the sole source of nitrogen and are sensitive to streptomycin. Our preliminary observations on some species of the family Solanaceae (Nicotiana debneyii, Petunia parodii) and of the family Leguminosae (Medicago sativa, Onobrychis viciifolia and Lotus corniculatus) have shown that their protoplast-derived colonies are capable of growth in a medium with nitrate as the sole source of nitrogen and that they are also sensitive to streptomycin. Such species thus satisfy a basic requirement for selection of any hybrids that might arise from fusions of protoplasts with this $N$. tabacum double mutant.

Since a number of auxotrophic (Müller and Grafe, 1978; Sidorov et al., 1981; Strauss et al., 1981; Negrutiu et al., 1983) and resistant mutants (Bourgin, 1978; Widholm, 1978; Cseplo and Maliga, 1982) have been isolated in higher plants, it should be possible to produce double mutants of other agronomically important species for somatic hybridisation studies. The double mutant approach may also be of value in somatic cell hybridisation of eukaryotic cells in general.

Acknowledgements. We thank Professor J. L. Jinks for seeds of N. rustica, Dr A. J. Müller for seeds of N. tabacum, Mr I. Gilder, Mr A. W. Johnson, Mrs J. A. Rayner, Mr D. Wilson for technical assistance and Mr B. V. Case for photographic work. This research was supported by the ARC and the British Petroleum Company Ltd. 


\section{REFERENCES}

BERRY, S. F., PATNAIK, G., COCKING, E. C. AND PENTAL, D. 1983. Plant regeneration from protoplasts of Nicotiana alata cv Crimson Bedder for somatic hybridization studies. Sci. Hort., 20, 281-285.

BOURGIN, J. P. 1978. Valine-resistant plants from in vitro selected tobacco cells. Mol. Gen. Genet, 161, 225-230.

CAMMAERTS, D. AND JACOBS, M. 1980. A simple electrophoretic procedure for the determination of the polypeptide composition of the subunits of Fraction 1 protein. Anal. Biochem., 97, 317-320.

CSEPLO, A. AND MALIGA, P. 1982. Lincomycin resistance, a new type of maternally inherited mutation in Nicotiana plumbaginifolia. Curr. Gen., 6, 105-109.

DOUGLAS, G. C., KELLER, w. A. AND SETTERFIELD, G. 1981. Somatic hybridisation between Nicotiana rustica and $N$. tabacum. II. Protoplast fusion and selection and regeneration of hybrid plants. Can. J. Bot., 59, 220-227.

HAMILl, J. D., PENTAL, D., COCKING, E. C. AND MÜlleR, A. J. 1983. Production of a nitrate reductase deficient streptomycin resistant mutant of Nicotiana tabacum for somatic hybridization studies. Heredity, 50, 197-200.

JINKS, J. L., CALIGARI, P. D. S. AND INGRAM, N. R. 1981. Gene transfer in Nicotiana rustica using irradiated pollen. Nature, 291, 586-588.

KELLER, W. A. AND MELCHERS, G. 1973. The effect of high $p \mathrm{H}$ and calcium on tobacco leaf protoplast fusion. Z. Naturforsch., 280, 737-741.

LOWRY, O. H., ROSEBROUGH, N. J., FARR, A. L. AND RANDALL, R. J. 1951. Protein measurement with the folin phenol reagent. J. Biol. Chem., 193, 265-275.

MALIGA, P., LAZAR, G., JOO, F., NAGY, A. H. AND MENCZEL, L. 1977. Restoration of morphogenic potential in Nicotiana by somatic hybridisation. Mol. Gen. Genet., 157, 291-296.

MELCHERS, G. AND LABIB, G. 1974. Somatic hybridization of plants by fusion of protoplasts. I. Selection of light resistant hybrids of "haploid" light sensitive varieties of tobacco. $\mathrm{Mol}$. Gen. Genet., 135, 277-294.

MÜLLER, A. J. AND GRAFE, R. 1978. Isolation and characterization of cell lines of Nicotiana tabacum lacking nitrate reductase. Mol. Gen. Genet., 161, 67-76.

MURASHIGE, T. AND SKOOG, F. 1962. A revised medium for rapid growth and bioassays with tobacco tissue cultures. Physiol. Plant., 15, 474-479.

NEGRUTIU, I., DIRKS, R. AND JACOBS, M. 1983. Regeneration of fully nitrate reductase-deficient mutants from protoplast culture of Nicotiana plumbaginifolia (Viviani). Theor. Appl. Genet. 66, 341-347.

PENTAL, D., hamill, J. D., COOPER-Bland, S., COCKING, E. C. AND MÜller, A. J. $1982 a$. Somatic hybridization studies with a nitrate reductase-deficient Nicotiana tabacum mutant. In Fujiwara, A. (ed.), Proc. Sth Intl. Cong. Plant Tissue and Cell Culture. Maruzen Press, Tokyo.

PENTAL, D., COOPER-BLAND, S., HARDING, K., COCKING, E. C. AND MÜLlER, A. J. $1982 b$. Cultural studies on nitrate reductase deficient Nicotiana tabacum mutant protoplasts. Z. Pflanzenphysiol., 105, 219-227.

POWER, J. B., BERRY, S. F., CHAPMAN, J. V. AND COCKING, E. C. 1980. Somatic hybridization of sexually incompatible Petunias: Petunia parodii and Petunia parviflora. Theor. Appl. Genet., $57,1-4$.

SIDOROV, V. A., MENCZEL, L. AND MALIGA, P. 1981. Isoleucine-requiring Nicotiana plant deficient in threonine deaminase. Nature, 294, 87-88.

SMITH, H. H., HAMILL, D. E., WEAVER, E. A. AND THOMPSON, K. H. 1970. Multiple molecular forms of peroxidases and esterases among Nicotiana species and amphiploids. $J$. Hered., $61,203-212$.

STRAUSS, A., BUCHER, B. AND KING, P. J. 1981. Isolation of biochemical mutants using haploid mesophyll protoplasts of Hyoscyamus muticus. I. A. $\mathrm{NO}_{3}^{-}$non-utilizing clone. Planta, 153, 75-80.

WIDHOLM, J. M. 1978. Selection and characterization of a Daucus carota L. cell line resistant to four amino acid analogues. J. Exp. Bot., 29, 1111-1116. 